\title{
Pembangkitan Kode Sampa MBROLA untuk Lirik Pupuh Pucung Berdasarkan Padalingsa dan Diftong
}

\author{
MBROLA Sampa Code Generation for Pupuh Pucung Lyrics Based on Padalingsa and \\ Diphtong
}

\author{
I Putu Eka Giri Gunawan ${ }^{1}$, I Gusti Agung Indrawan ${ }^{2}$ \\ ${ }^{1,2}$ Teknik Informatika, STMIK STIKOM Indonesia \\ E-mail: 1eka.giri@stiki-indonesia.ac.id, ${ }^{2}$ agung.indrawan@stiki-indonesia.ac.id
}

\begin{abstract}
Abstrak
Kurangnya minat masyarakat untuk belajar tembang bali akan mengakibatkan semakin hilangnya budaya bali. Salah satu faktor peyebab kurang tertarik nya masyarakat untuk belajar tembang bali adalah media pembelajaran tembang bali yang kurang menarik dan tidak interaktif. Pupuh pucung merupakan salah satu bagian dari sekar alit yang merupakan bagian tembang bali. Sekar alit/pupuh memiliki aturan dalam penulisan liriknya yang disebut dengan padalingsa yang terdiri dari guru wilangan yaitu jumlah suku kata dalam setiap barisnya, guru dingdong yaitu huruf vokal pada kata terakhir setiap barisnya dan guru gatra yaitu jumlah baris dalam satu baitnya. Penelitian ini akan menciptakan suatu aplikasi yang interaktif yang bisa digunakan untuk mencoba lirik dari pupuh pucung sesuai dengan aturan padalingsa pupuh pucung. Penelitian ini membahas bagaimana analisis dan konversi lirik pupuh pucung ke kode sampa yang digunakan di program sintesis suara MBROLA. Hasil dari penelitian ini adalah kode sampa MBROLA yang dibangkitkan berdasarkan aturan padalingsa dan diftong bahasa bali.
\end{abstract}

Kata kunci: tembang bali, pupuh pucung, padalingsa, kode sampa, MBROLA

\section{Abstract}

Lack of people interest in learning traditional balinese songs will result in loss of balinese culture. One of the factors causing the people's lack of interest in learning traditional balinese songs is an unattractive and noninteractive media. Pupuh pucung which translated into english mean pucung poem, is part of sekar alit which is part of tradional balinese song. Sekar alit/pupuh has rules in writing the lyrics called padalingsa which consists of "guru wilangan" which is the number of syllables in each line, the "guru dingdong" which is the vowel in the last word of each line and the "guru gatra" which is the number of lines in one stanza. This research will create an interactive application that can be used to try the lyrics of pupuh pucung in accordance with padalingsa. This research discusses how to analyze and convert pupuh pucung lyrics to sampa code used in MBROLA voice synthesis program. The results of this research are sampa code used in MBROLA, which is generated based on the padalingsa and diphthong rules of the balinese language.

Keywords: balinese traditional song, pupuh pucung, padalingsa, sampa code, MBROLA

\section{PENDAHULUAN}

Dharma Gita atau seni suara adalah suatu pernyataan atau gambaran dari jiwa manusia, yang dinyatakan dalam bentuk deretan nada yang diciptakan atau dicetak maupun yang lanjut disuarakan secara vokal ataupun instrumental. Dharma Gita dapat dikelompokkan menjadi empat jenis antara lain sekar rare, sekar alit, sekar madya dan sekar agung. Sekar alit atau tembang macepat ini juga sering disebut dengan pupuh, yang dalam penulisannya menggunakan aturan yang disebut padalingsa. Aturan padalingsa pada pupuh antara lain guru wilangan yaitu 
jumlah suku kata dalam setiap barisnya, guru dingdong yaitu huruf vokal pada kata terakhir setiap barisnya dan guru gatra yaitu jumlah baris dalam satu baitnya [1]. Berdasarkan aturan padalingsa-nya, sekar alit dapat dikelompokkan menjadi beberapa jenis antara lain pupuh sinom, pupuh ginada, pupuh ginanti, pupuh pucung, pupuh maskumambang dan lain-lain.

Aturan padalingsa yang terdapat pada sekar alit dapat mempermudah dalam menuliskan syair-syair dari sekar alit tersebut. Syair-syair yang sudah ditulis berdasarkan aturan padalingsa harus dinyanyikan dengan nada dan ritme dari pupuh itu masing-masing. Nada dan ritme menyanyikan pupuh juga dapat dipengaruhi oleh suara dari yang menyanyikan. Untuk mengatasi kesulitan dalam belajar menyanyikan pupuh perlu dikembangkan suatu sistem yang dapat menyanyikan pupuh dengan nada dan ritme dasar yang tetap dengan perubahan pada liriknya. Teknologi text-to-speech atau merubah teks menjadi suara adalah salah satu cara untuk membantu mengatasi kesulitan tersebut. Teknologi text-to-speech ini dapat merubah teks syair yang dibuat menjadi suara dalam bentuk nyanyian. Salah satu software text-to-speech adalah MBROLA. MBROLA menggunakan kode sampa sebagai dasar speech synthesis. Untuk membangun text-to-speech dengan MBROLA menggunakan database diphone. Database diphone Indonesia pertama dibuat oleh Akhmad Arman di Belgia pada tahun 2000 yang disebut dengan id1 [2].

Penelitian text-to-speech bahasa daerah Bali sudah dilakukan oleh [3]. Penelitian tersebut mengubah teks bahasa Bali dalam huruf latin menjadi ucapan yang disimpan dalam bentuk file wave audio form (wav). Penelitian text-to-speech bahasa daerah Bugis Wajo dilakukan oleh [4]. Penelitian tersebut mengubah teks bahasa Bugis Wajo menjadi speech berbahasa Bugis Wajo. Penelitian tersebut memotong kata dalam bahasa Bugis Wajo menjadi suku-kata dengan menganalisis kurva prosodi pada jumlah suku kata dalam bahasa Bugis Wajo [4]. Penelitian manipulasi prosodi untuk menambahkan emosi pada text-to-speech sudah dilakukan oleh [5] dimana penelitian ini mengelompokkan emosi menjadi enam jenis filter emosi yaitu takut, marah, sedih, senang, jijik/memuakkan dan terkejut.

Penelitian ini akan mengembangkan rancang bangung konversi lirik pupuh pucung ke kode sampa MBROLA. Proses pemenggalan lirik pupuh pucung agar sesuai dengan aturan padalingsa sudah dilakukan oleh [6]. Aturan padalingsa pupuh pucung akan dikonversi ke kode sampa. Pada proses akuisisi data akan digunakan form inputan yang sesuai dengan aturan padalingsa pupuh pucung seperti jumlah suku kata pada setiap baris dan jumlah baris pada setiap bait. Kemudian lirik pupuh pucung divalidasi agar sesuai dengan aturan padalingsa pupuh pucung. Lirik yang sudah sesuai dengan atauran padalingsa dilakukan perbaikan/penyesuaian huruf pada suku kata untuk mendapatkan output suara yang lebih natural. Lirik yang sudah disesuaikan dikonversikan ke dalam bentuk fonem dan dilanjutkan ke dalam bentuk kode sampa. Kode sampa merupakan bentuk konversi fonem yang dapat dibaca oleh MBROLA. Hasil dari penelitian ini adalah aplikasi interaktif konversi lirik pupuh pucung ke kode sampa MBROLA. Secara umum proses dalam sistem TTS terdiri dari natural language processing (NLP) yang berupa modul konversi teks ke fonem yang menghasilkan transkripsi fonetik beserta informasi dan ritme (dikenal dengan prosodi) dan digital signal processing (DSP) yang berupa modul konversi fonem ke ucapan [7]. Kode sampa hasil penelitian ini yang merupakan hasil pengolahan fonem dapat digunakan untuk melakukan speech synthesis pupuh pucung pada MBROLA dengan menambahkan prosodi yang sesuai dengan nada pupuh pucung. Penambahan prosodi agar bisa menghasilkan nyanyian pupuh pucung dapat dilakukan dengan manipulasi pada prosodi yang akan ditambahkan sehingga menghasil kan suara berupa nyanyian pupuh pucung. Implementasi manipulasi pada prosodi sudah dilakukan oleh [8].

\section{METODE PENELITIAN}

Sistem text-to-speech pada prinsipnya terdiri dari dua sub sistem yaitu bagian konverter teks ke fonem dan bagian konverter fonem ke ucapan [3]. Penelitian ini secara umum melakukan tahapan konversi teks ke fonem dan dilanjutkan ke dalam bentuk kode sampa. Gambaran umum rancang bangun konversi lirik pupuh pucung ke kode sampa MBROLA dapat 
dilihat pada Gambar 1. Proses akuisisi data merupakan proses pengolahan terhadap teks masukan user, pada tahap ini pada tahap ini teks lirik mengalami proses validasi terhadap aturan padalingsa pupuh pucung dan perbaikan teks lirik. Proses berikutnya adalah proses konversi teks ke fonem dimana pada proses ini, teks lirik yang sudah diperbaiki akan dikonversi ke dalam bentuk kode sampa.

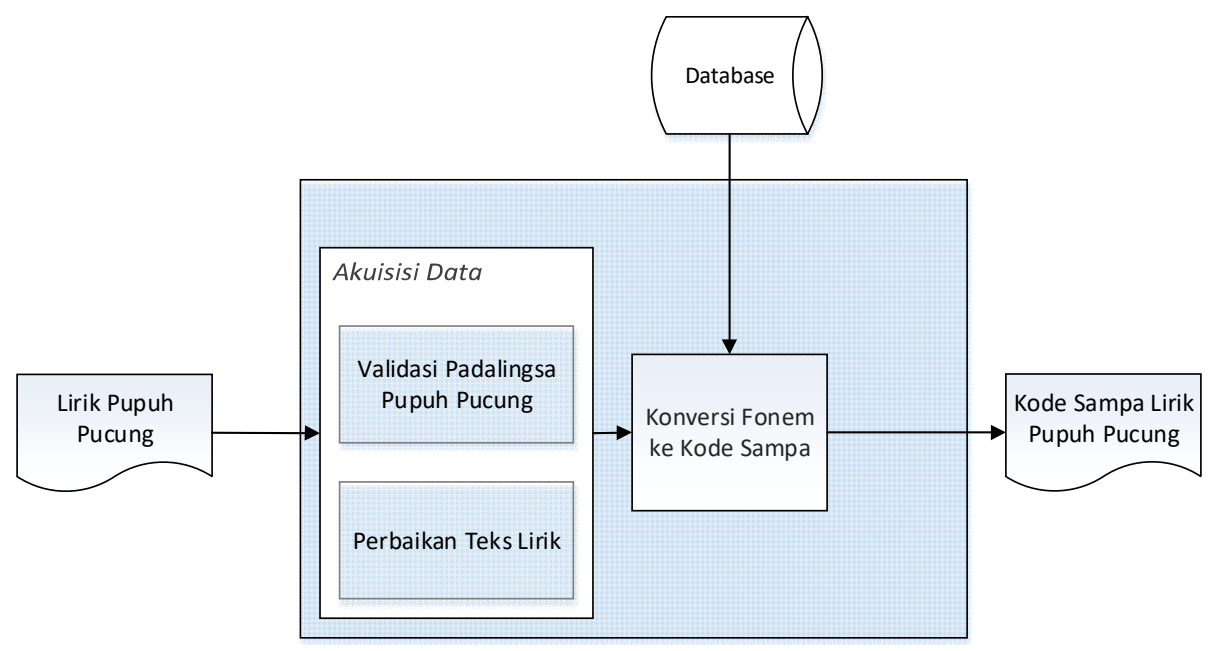

Gambar 1. Gambaran Umum Sistem

\subsection{Akuisisi Data}

Proses akuisisi data dilakukan dengan menggunakan form input yang disesuaikan dengan aturan padalingsa pupuh pucung. Pada tahap akuisisi data juga akan dilakukan proses validasi dan perbaikan teks masukan user.

\subsection{Validasi Padalingsa Pupuh Pucung}

Padalingsa adalah aturan dalam menulis pupuh yang terdiri dari Guru Wilangan, Guru Dingdong dan Guru Gatra. Padalingsa pupuh pucung adalah seperti berikut:

\section{$4 \mathrm{u} 8 \mathrm{u} 6 \mathrm{a} 8 \mathrm{i} 4 \mathrm{u} 8 \mathrm{a}$}

Sesuai dengan aturan padalingsa tersebut, form input data dibuat sesuai dengan aturan padalingsa pupuh pucung sehingga memudahkan pengguna dalam menulis lirik pupuh pucung. Gambar 2 menampilkan rancangan form input lirik pupuh pucung.

\subsection{Perbaikan/Penyesuaian Suku Kata Teks Lirik}

Bahasa bali dalam perkembangannya mengalami evolusi fonologis ditandai dengan adanya perubahan bunyi. Perubahan-perubahan yang ditemukan meliputi pelepasan bunyi, metatesis, perubahan bunyi tak biasa dan perubahan vocal dan konsonan [9]. Pada proses ini dilakukan untuk memperbaiki pelepasan bunyi yaitu perbaikan atau penambahan huruf pada suatu kata dari lirik yang diinputkan user. Fonem-fonem vokal bahasa bali hanya berupa fonemfonem tunggal sebab ternyata fonem-fonem vokal yang berupa diftong, yaitu gabungan dua vokal tunggal yang memiliki puncak kenyaringan yang tunggal tidak ditemukan dalam bahasa bali [10]. Proses perbaikan ini diperlukan untuk memenuhi aturan fonem dalam bahasa bali. 


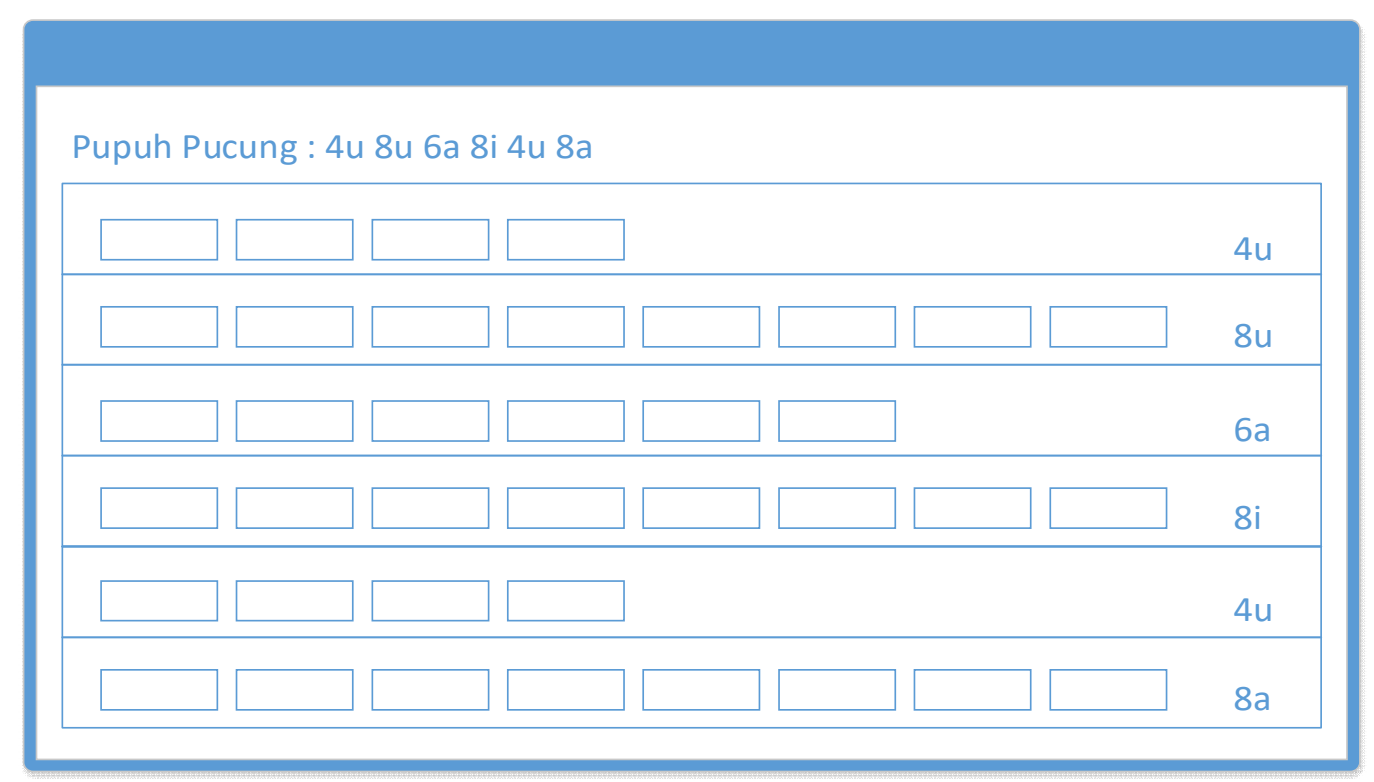

Gambar 2. Rancangan Form Lirik Pupuh Pucung

Pada proses perbaikan juga dilakukan penambahan huruf pada suatu kata yang bertujuan untuk memperhalus hasil pengucapan. Penambahan huruf untuk memperhalus suara dilakukan dengan melakukan pengamatan pada kata yang memiliki gabungan dua fonem vokal bahasa bali yang bukan merupakan diftong. Gabungan dua buah fonem vokal yang diawali dengan fonem /i, e/ akan dilakukan perbaikan dengan menyisipkan fonem /y/ ditengahnya. Gabungan dua buah fonem vokal yang diawali dengan fonem /u, o/ akan dilakukan perbaikan dengan menyisipkan fonem $/ \mathrm{w} /$ ditengahnya. Daftar aturan normalisasi teks yang dirancang dapat dilihat di Tabel 1.

Tabel 1. Aturan Perbaikan Lirik Fonem Bahasa Bali

\begin{tabular}{|l|l|l|}
\hline $\begin{array}{c}\text { Teks } \\
\text { Awal }\end{array}$ & $\begin{array}{c}\text { Hasil } \\
\text { Perbaikan }\end{array}$ & Contoh Penerapan \\
\hline au & o & Danau - Dano \\
\hline ia & iya & Liang - Liyang \\
\hline iu & iyu & Liu - liyu \\
\hline ie & iye & - \\
\hline iE & iyE & - \\
\hline io & iyo & - \\
\hline ea & eya & - \\
\hline ei & eyi & - \\
\hline eu & eyu & - \\
\hline eo & eyo & - \\
\hline ua & uwa & Lua - luwa \\
\hline ui & uwi & Luih - Luwih \\
\hline ue & uwe & - \\
\hline uE & uwE & \\
\hline uo & uwo & - \\
\hline oa & owa & - \\
\hline oi & owi & - \\
\hline ou & owu & - \\
\hline
\end{tabular}




\begin{tabular}{|l|l|l|}
\hline $\begin{array}{c}\text { Teks } \\
\text { Awal }\end{array}$ & $\begin{array}{c}\text { Hasil } \\
\text { Perbaikan }\end{array}$ & Contoh Penerapan \\
\hline oe & owe & - \\
\hline oE & owE & - \\
\hline
\end{tabular}

\subsection{Konversi fonem ke kode sampa}

Konversi fonem ke kode sampa merupakan proses konversi dari fonem hasil perbaikan ke dalam bentuk kode sampa MBROLA. Bahasa Indonesia secara keseluruhan memiliki 26 jenis alfabet dan 29 jenis fonem. Tidak semua alfabet dalam bahasa indonesia memiliki representasi fonem yang sama. Dalam mesin MBROLA, fonem akan direpresentasikan dengan kode sampa fonem, durasi serta pitch-nya. Aturan kode sampa fonem bahasa Indonesia dalam mesin MBROLA dapat dilihat di Tabel 2.

Tabel 2. Tabel Kode Sampa MBROLA Bahasa Indonesia

\begin{tabular}{|c|c|c|}
\hline Fonem & Kode Sampa & Contoh \\
\hline $\mathrm{p}$ & $\mathrm{p}$ & apa \\
\hline $\mathrm{b}$ & $\mathrm{b}$ & abang \\
\hline $\mathrm{t}$ & $\mathrm{t}$ & atap \\
\hline $\mathrm{d}$ & d & tadi \\
\hline $\mathrm{k}$ & $\mathrm{k}$ & akan \\
\hline g & $\mathrm{g}$ & gila \\
\hline $\mathrm{c}$ & $\mathrm{tS}$ & cari \\
\hline $\mathrm{j}$ & $\mathrm{dZ}$ & jadi \\
\hline$f$ & $\mathrm{f}$ & kafan \\
\hline $\mathrm{s}$ & $\mathrm{s}$ & kasar \\
\hline $\mathrm{z}$ & $\mathrm{z}$ & zebra \\
\hline $\mathrm{h}$ & $\mathrm{h}$ & hitam \\
\hline $\mathrm{m}$ & $\mathrm{m}$ & aman \\
\hline $\mathrm{n}$ & $\mathrm{n}$ & anda \\
\hline ng & $\mathrm{N}$ & angka \\
\hline$r$ & $\mathrm{r}$ & armada \\
\hline 1 & 1 & alamat \\
\hline $\mathrm{w}$ & $\mathrm{W}$ & bawa \\
\hline $\mathrm{y}$ & $\mathrm{j}$ & bahaya \\
\hline ny & $\mathrm{nY}$ & kenyang \\
\hline $\mathrm{a}$ & $\mathrm{V}$ & bapa \\
\hline$\hat{\mathrm{e}}$ & @ & petang \\
\hline $\mathrm{e}$ & $E$ & medan \\
\hline $\mathrm{i}$ & I & bila \\
\hline o & Q & mohon \\
\hline $\mathrm{u}$ & $\mathrm{U}$ & bukan \\
\hline ai & aI & santai \\
\hline oi & OI & amboi \\
\hline $\mathrm{au}$ & $\mathrm{aU}$ & lampau \\
\hline . & - & Jeda \\
\hline
\end{tabular}




\section{HASIL DAN PEMBAHASAN}

Pada bagian hasil dan pembahasan akan dilakukan uji coba konversi satu jenis pupuh pucung ke dalam bentuk kode sampa MBROLA.

\subsection{Validasi Padalingsa Pupuh Pucung}

Proses proses validasi lirik dilakukan dengan menggunakan form input yang disesuaikan dengan aturan padalingsa pupuh pucung. Berikut tampilan form input lirik pupuh pucung.

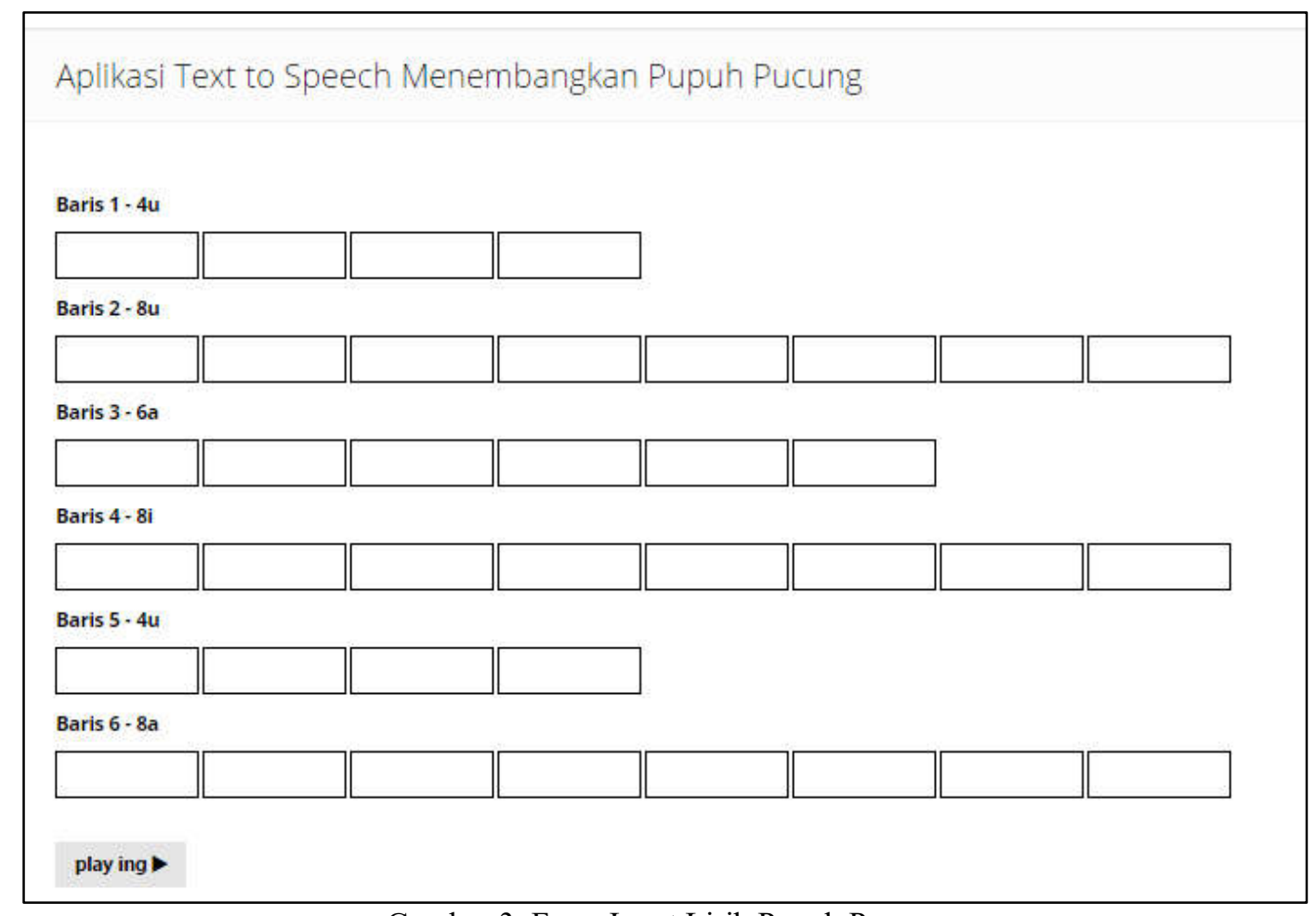

Gambar 3. Form Input Lirik Pupuh Pucung

Form input disesuaikan dengan aturan guru gatra pupuh pucung yaitu jumlah baris dalam satu bait yaitu enam baris. Jumlah suku kata dan huruf vokal terakhir dalam setiap baris juga disesuaikan dengan aturan guru wilangan dan guru dingdong pupuh pucung yaitu baris pertama terdiri dari empat suku kata dengan huruf vokal terakhir ' $u$ ', baris kedua terdiri dari delapan suku kata dengan huruf vokal terakhir ' $u$ ', baris ketiga terdiri dari enam suku kata dengan huruf vokal terakhir 'a', baris keempat terdiri dari delapan suku kata dengan huruf vokal terakhir ' $\mathrm{i}$ ', baris kelima terdiri dari empat suku kata dengan huruf vokal terakhir ' $u$ ' dan baris keenam terdiri dari delapan suku kata dengan huruf vokal terakhir 'a'. Sesuai dengan gambaran umum sistem, pada akuisisi data terdapat dua proses yang dilakukan antara lain validasi padalingsa pupuh pucung dan perbaikan teks lirik pupuh pucung.

\subsection{Perbaikan/Penyesuaian Suku Kata Teks Lirik}

Proses perbaikan teks lirik dilakukan dengan melakukan perubahan atau penambahan huruf pada suatu kata yang bertujuan untuk memperhalus pengucapan dan mempermudah pembentukan fonem. Hasil lirik yang sudah sesuai dengan atauran padalingsa pupuh pucung dilakukan perbaikan teks lirik. Berikut hasil perbaikan teks lirik pupuh pucung. 
Bibi anu

Lamun payu luas mandus

Antenge tekekang

Yatnain ngabe mesui

Tiuk puntul

Bawang anggon pesikepan [11]

Proses perbaikan dari lirik diatas akan menjadi seperti berikut:

Bibi anu

Lamun payu luwas mandus

Antenge tekekang

Yatnain ngabe mesuwi

Tiyuk puntul

Bawang anggon pesikepan

Pada proses perbaikan terlihat kata luas mengalami perbaikan menjadi luwas, kata mesui mengalami perbaikan menjadi mesuwi dan kata tiuk mengalami perbaikan menjadi tiyuk. Pada kata yatnain terdapat gabungan dua fonem vokal yaitu fonem /a, i/, gabungan fonem tersebut tidak mengalami perubahan karena bukan merupakan diftong.

\subsection{Konversi Fonem ke Kode Sampa}

Pada proses ini, lirik hasil perbaikan akan dikonversi ke dalam bentuk kode sampa sesuai dengan tabel kode sampa Bahasa Indonesia. Berikut merupakan hasil konversi lirik pupuh pucung ke dalam bentuk kode sampa.

Tabel 3. Konversi Fonem Lirik Pupuh Pucung ke Kode Sampa

\begin{tabular}{|c|c|c|c|c|c|c|c|c|c|c|c|c|c|c|c|c|c|c|c|c|c|c|}
\hline$b$ & i & $b$ & i & & $a$ & $n$ & $\mathrm{u}$ & & & & & & & & & & & & & & & \\
\hline$b$ & I & $b$ & I & - & V & $\mathrm{n}$ & $U$ & & & & & & & & & & & & & & & \\
\hline I & $a$ & $\mathrm{~m}$ & $\mathrm{u}$ & $n$ & & $p$ & a & $y$ & $\mathrm{u}$ & & 1 & $\mathrm{u}$ & $w$ & $a$ & $\mathrm{~s}$ & & $\mathrm{~m}$ & $\mathrm{a}$ & $\mathrm{n}$ & $d$ & $\mathrm{u}$ & $S$ \\
\hline I & V & $\mathrm{m}$ & U & $n$ & - & $p$ & V & j & $\mathrm{u}$ & - & 1 & U & $w$ & V & 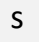 & _ & $\mathrm{m}$ & V & $\mathrm{n}$ & d & U & $S$ \\
\hline$a$ & $n$ & $t$ & $E$ & ng & e & & $t$ & $E$ & $\mathrm{k}$ & $\mathrm{E}$ & $\mathrm{k}$ & $a$ & ng & & & & & & & & & \\
\hline V & $n$ & $\mathrm{t}$ & @ & $\mathrm{N}$ & $\mathrm{E}$ & - & $\mathrm{t}$ & @ & $\mathrm{k}$ & @ & $\mathrm{k}$ & V & $\mathrm{N}$ & & & & & & & & & \\
\hline y & $a$ & $\mathrm{t}$ & $n$ & $a$ & $i$ & $n$ & & ng & & $b$ & $E$ & & $\mathrm{~m}$ & $E$ & $\mathrm{~s}$ & u & $w$ & $\mathrm{i}$ & & & & \\
\hline j & V & $\mathrm{t}$ & $n$ & V & 1 & $n$ & - & $\mathrm{NV}$ & & $b$ & @ & - & $\mathrm{m}$ & @ & $\mathrm{s}$ & U & $w$ & 1 & & & & \\
\hline $\mathrm{t}$ & $\mathrm{i}$ & $y$ & $\mathrm{u}$ & k & & $p$ & $\mathrm{u}$ & $\mathrm{n}$ & $\mathrm{t}$ & $\mathrm{u}$ & 1 & & & & & & & & & & & \\
\hline $\mathrm{t}$ & 1 & j & $U$ & k & - & $p$ & $U$ & $\mathrm{n}$ & $\mathrm{t}$ & $U$ & 1 & & & & & & & & & & & \\
\hline$b$ & $a$ & $w$ & a & ng & & $a$ & ng & g & 0 & $\mathrm{n}$ & & $p$ & $a$ & $\mathrm{~s}$ & i & k & $E$ & $p$ & $a$ & $\mathrm{n}$ & & \\
\hline b & V & $w$ & V & $N$ & & V & $\mathrm{N}$ & $\mathrm{g}$ & $Q$ & $n$ & & $p$ & V & $\mathrm{s}$ & 1 & k & @ & $p$ & V & $\mathrm{n}$ & & \\
\hline
\end{tabular}


Kode sampa ini kemudian dapat digunakan sebagai lirik dasar untuk melakukan sintesis suara pupuh pucung pada MBROLA dengan menambahkan prosodi yang sesuai dengan nada pupuh pucung.

\section{KESIMPULAN}

Validasi lirik pupuh pucung dilakukan pada form input lirik pupuh pucung yang dirancang sesuai dengan aturan padalingsa pupuh pucung sehingga dapat mempermudah pengguna dalam membuat lirik. Jumlah baris dalam form input disesuaikan dengan aturan guru gatra pupuh pucung yaitu jumlah baris dalam satu bait yaitu enam baris. Jumlah suku kata dalam setiap baris juga disesuaikan dengan aturan guru wilangan. Validasi huruf vokal terakhir pada setiap baris disesuaikan dengan aturan guru dingdong pupuh pucung.

\section{SARAN}

Penelitian ini menggunakan lirik pupuh pucung yang merupakan bagian dari sekar alit. Hasil penelitian adalah bentuk kode sampa MBROLA dari lirik pupuh pucung yang digunakan sebagai contoh. Untuk pengembangan penelitian selanjutnya dapat dilakukan pada jenis sekar alit lainnya yang memiliki aturan padalingsa yang berbeda. Pengembangan penelitian lain yang dapat dilakukan adalah pembangkitan prosodi untuk kode sampa pupuh pucung sehingga bisa menghasilkan lagu pupuh pucung.

\section{UCAPAN TERIMA KASIH}

Terima kasih diucapkan kepada LPPM STMIK STIKOM Indonesia yang telah membiayai penelitian ini melalui skema Penelitian dan Pengembangan Dosen STIKI 2019.

\section{DAFTAR PUSTAKA}

[1] I. B. M. W. Parta, “Analisis Stilistika Dalam Pupuh-Pupuh,” Widya Accarya, vol. 3, no. $1,2014$.

[2] A. A. Arman, "First Indonesian Text to Speech - Indo TTS," 2003. [Online]. Available: http://indotts.melsa.net.id/index.html. [Accessed: 02-Nov-2019].

[3] P. M. M. Pramadewi, M. W. A. Kesiman, and I. G. M. Darmawiguna, "Pengembangan Aplikasi Text to Speech untuk Bahasa Bali," J. Nas. Pendidik. Tek. Inform., vol. 2, no. 3, p. 219, 2013, doi: 10.23887/janapati.v2i3.9807.

[4] A. B. P. Negara, N. Safriadi, A. Perwitasari, and M. D. M. Putri, "Text-To-Speech Engine Generik Bahasa Bugis Wajo," in Seminar Nasional APTIKOM 2016, 2016, vol. 1, no. 1, pp. 774-779.

[5] E. Mulyanto, E. M. Yuniarno, and M. H. Purnomo, "Adding an Emotions Filter to Javanese Text-to-Speech System," 2018 Int. Conf. Comput. Eng. Netw. Intell. Multimedia, CENIM 2018 - Proceeding, pp. 142-146, 2018, doi: 10.1109/CENIM.2018.8711229.

[6] A. A., P. Wira, and T. Wulandari, "Web-based Implementation of Finite State Automata Method on Lyrics Recognition System of Balinese Song 'Pupuh,"' Int. J. Comput. Appl., vol. 149, no. 4, pp. 32-37, 2016, doi: 10.5120/ijca2016911389.

[7] I. I. Tritoasmoro, "Text-To-Speech Bahasa Indonesia Menggunakan Concatenation Synthesizer Berbasis Fonem," Semin. Nas. Sist. dan Inform. 2006, pp. 171-176, 2006.

[8] S. U. Prini, A. S. Prihatmanto, and D. A. Jatmiko, "Study and Implementation of Prosody Manipulation Method for Indonesian Speech Synthesis System," 2018 Int. Conf. Inf. Technol. Syst. Innov. ICITSI 2018 - Proc., pp. 121-126, 2018, doi: 10.1109/ICITSI.2018.8696028.

[9] P. E. G. Yasa, A. M. Mbete, and N. M. Dhanawaty, "Evolusi Fonologis Leksikon Dalam 
Sejarah Perkembangan Bahasa Bali," Linguistika, vol. 25, no. 2, pp. 165-174, 2018, doi: https://doi.org/10.24843/ling.2018.v25.i02.p10.

[10] I. N. Sulaga, Tata Bahasa Baku Bahasa Bali. Denpasar: Pemerintah Propinsi Daerah Tingkat I Bali, 1996.

[11] K. W. A. Mahardika, "Lantunan Masa Kecil dalam 'Lullabybianu," J. Music Sci. Technol. Ind., vol. 1, no. 1, pp. 73-98, 2018, doi: https://doi.org/10.31091/jomsti.v1i1.505. 